Family was the main source of referral ( $45 \%$ of cases), whereas general practitioners referred $20 \%$ of cases only, and so were shown to have a lesser role in the pathways to psychiatric care. This is contrary to the important role of primary care in high-income countries (Edwards \& McGorry, 2002; Shiers \& Lester, 2004).

The study results may not provide an accurate reflection of DUP. However, the factors found to be associated with delayed access to care are important and need to be carefully addressed to improve access to psychiatric care for those with an FEP. Larger, longer studies are needed.

\section{Conclusion}

The study results indicate that cultural factors, lack of knowledge about mental illness and services, stigma and financial factors probably influence help-seeking behaviour, which in turn may play a significant role in delayed access to care in rural Egypt. Programmes to improve public awareness of mental illness and the available services and to address stigma are needed. Further development of the healthcare system and service model in Egypt is likely to help.

\section{References}

Beiser, M., Erickson, D., Fleming, J. A. E., et al (1993) Establishing the onset of psychotic illness. American Journal of Psychiatry, 150, 1349-1354.

Brunet, K., Birchwood, M., Lester, H., et al (2007) Delays in mental health services and duration of untreated psychosis. Psychiatric Bulletin, 31, 408-410.
Edwards, J. \& McGorry, P. (2002) Key Service Elements. Early Recognition and Assistance: Implementing Early Intervention in Psychosis. A Guide to Establishing Early Psychosis Services. Martin Dunitz.

El-Adl, M. \& Balhaj, T. (2008) Stigma of mental illness (SMI): views of the public in an Arabic culture. Arab Journal of Psychiatry, 19, 57-65.

Fahmy, E., Michael V., Elsheikh, H., et al (2004) Knowledge, attitude and behaviour towards mental illness across secondary schools in Benha city. Egyptian Journal of Psychiatry, 23, 30-37.

Ho, B.-C., Alicata, D., Ward, J., et al (2003) Untreated initial psychosis: relation to cognitive deficits and brain morphology in first episode schizophrenia. American Journal of Psychiatry, 160, 142-148.

Larsen, T. K., Johannsen, J. O. \& Opjordsmoen, S. (1998) First episode schizophrenia with long duration of untreated psychosis. British Journal of Psychiatry, 172 (suppl. 33), s45-s52.

Lincoln, C. \& McGorry, P. (2000) Pathways to care in early psychosis: clinical and consumer perspectives. In The Recognition and Management of Early Psychosis. A Preventive Approach (eds P. McGorry \& H. Jackson), pp. 51-79. Cambridge University Press.

Loebel, A. D., Lieberman, J. A., Alvir, J. M. J., et al (1992) Duration of psychosis and outcome in first episode schizophrenia. American Journal of Psychiatry, 149, 1183-1188.

McCrone, P. \& Knapp, M. (2007) Economic evaluation of early intervention services. British Journal of Psychiatry, 191 (suppl. 51), s19-s22.

McGlashan, T. H. (1987) Recovery style from mental illness and long-term outcome. Journal of Nervous and Mental Disease, 175, 681-685.

Mihalopoulos, C., McGorry, P. D. \& Carter, R. C. (1999) Is phase-specific, community oriented treatment of early psychosis an economically viable method of improving outcome? Acta Psychiatrica Scandinavica, $100,47-55$.

Shiers, D. \& Lester, H. (2004) Early intervention for first episode psychosis needs greater involvement of primary care professionals for its success. BMJ, 328, 1451-1452.

Wyatt, R. J., Damiani, M. \& Henter, I. D. (1998) First episode schizophrenia. British Journal of Psychiatry, 172 (suppl. 33), s77-s83.

Yung, A. \& McGorry, P. (2007) Prediction of psychosis: setting the stage. British Journal of Psychiatry, 191 (suppl. 1), s1-s8.

\title{
Bagh regrows - earthquake survivors as catalysts of community and personal reconstruction
}

\author{
Tanzeel R. Ansari ${ }^{1}$ and R. J. Ørner ${ }^{2}$
}

${ }^{1}$ Specialist Registrar, General Adult Psychiatry, Nottinghamshire Healthcare NHS Trust, Nottingham Alcohol \& Drug Team, Wells Road Centre, The Wells Road, Nottingham NG3 3AA, UK, email t.ansari@doctors.org.uk ${ }^{2}$ Visiting Professor in Clinical Psychology, Faculty of Health, Life and Social Sciences, University of Lincoln, Lincoln, UK

\begin{abstract}
n our age of frequent natural disasters in this increasingly interdependent world, there is a pressing need to understand better the processes of societal adjustment. The Kashmir earthquake of 8 October 2005 brought human suffering on a massive scale. High rates of psychiatric morbidity have been reported (Niaz et al, 2006; see also http://emdrpakistan.com). Whereas the relevance of the application of Western, secularised, psychological treatment models to this group is outside the scope of this paper, survivors have faced catastrophe and destruction of both their internal and external realities.

More can be learnt about how some survivors who are in crisis achieve the transition to active helpers. Points for
\end{abstract}

consideration are the many studies that document the psychiatric and psychological impact of disasters on survivor populations (Van Griensven et al, 2006), as well as the significant risks that accrue to emergency and rescue personnel mobilised to respond to major incidents (Cetin et al, 2005; Hagh-Shenas et al, 2005).

A special opportunity to investigate early subjective accounts of how such developments can occur arose at a local competence and resource re-building initiative for survivors in December 2005 organised by the Qatar Red Crescent Society's Psychological Support Programme in Bagh (Urdu for 'garden'), the disaster-struck capital of Bagh District, Pakistan-Administered Kashmir. 
Table 1 Respondents' characteristics

$\begin{array}{lc}\text { Characteristics } & \text { Sample } \\ \begin{array}{l}\text { Gender } \\ \text { Number of males }\end{array} & 11 \\ \text { Number of females } & 10 \\ \text { Age (years) } & \\ \text { Range } & 23-48 \\ \text { Mean } & 33.8 \\ & \\ \text { Participants' level of education } & 2 \\ \text { Number with secondary education } & 19 \\ \text { Number with university education } & \\ \text { Profession } & 17 \\ \text { Number of school teachers } & 4 \\ \text { Number of religious teachers/leaders } & \end{array}$

\section{Method}

\section{Sample}

Participants were volunteers attending the Qatar Red Crescent Society's Psychological Support Programme during late December 2005. Two schools in and near Bagh were used for the training and interviews. Participants were paid transport expenses to be able to attend the programme. Of 96 attendees, 21 consented to be interviewed.

\section{Interview}

Semi-structured interviews in Urdu were audio-recorded approximately 2 months after the disaster, at a time when small tremors were still occurring. Interviews were carried out in the schools, and no adaptations were made to the original format. Questions used as cues covered demographic information and coping strategies used in the aftermath of the earthquake, as well as observations of how other survivors adjusted. Responses were recorded in their entirety. Female participants were interviewed with a female chaperone present. Recordings were translated and transcribed into English.

\section{Analysis}

Transcripts were initially examined independently by both authors to identify and label key elements in survivors' narratives using QSR N6 Qualitative Data Analysis software (QSR International Pty Ltd, Victoria, Australia), with differences reconciled by consensus. The most salient themes were then agreed and transcripts were reanalysed to extract statements describing how coping and adjustment were achieved. Statements were grouped into the salient themes and emergent progressions postulated.

\section{Results}

The respondents' characteristics are summarised in Table 1. All participants reported huge personal and communal losses during and after the earthquake, which evoked significant distress, hopelessness and despair. From situations of devastation and loss, survivor imperatives reached beyond those of addressing basic physical survival needs (food, water, shelter). Two recurrent themes emerged in survivors' narratives of coping and adjustment. Reports point to the importance of both social cohesion and narrative coherence for those

Table 2 Summary of the postulated social cohesion and narrative coherence phases

\begin{tabular}{|c|c|}
\hline Phase of survivor progression & Quotes from respondents \\
\hline $\begin{array}{l}1 \text { The phases of social cohesion } \\
\text { - The impact: observed disintegration, } \\
\text { chaos and feeling overwhelmed } \\
\text { - Personal survival imperatives: personal } \\
\text { coping and reconstruction for survival } \\
\text { - Broadening awareness: shared adversity } \\
\text { as an integrating force }\end{array}$ & $\begin{array}{l}\text { 'after the earthquake ... people were numb. Each household was occupied with itself...' } \\
\text { 'people had nothing ... there was nothing to eat, to drink, and it was the month of Ramadan...' } \\
\text { 'we kept steadfast. We rebuilt our homes...' } \\
\text { 'I kept working to get a school shelter built ... it helped to raise my spirits ... my confidence } \\
\text { increased by itself and now I am fine...' } \\
\text { 'they stopped asking what was their loss ... the community-wide situation became apparent; } \\
\text { people felt better able to cope when we realised that everyone was affected...' } \\
\text { 'as teams of doctors and other volunteers arrived, people started to feel that we need to do } \\
\text { something to keep living...' } \\
\text { 'we have to continue our lives ... we have seen that there have been many marriages after this.' } \\
\text { 'I give a lot of encouragement to the children here ... if I can help even } 10-15 \text { of them to } \\
\text { return to their normal lives this would be a big thing for me.' } \\
\text { 'I kept working to get a school shelter built...' } \\
\text { 'people are building temporary shelters because this is a very cold region...' } \\
\text { 'education is being continued in school, and the children ... don't want to waste a year' } \\
\text { 'I also started to go to school so that life returns to normality and help children cope.' } \\
\text { 'we try to help ourselves ... we teachers are making great efforts so that the children's minds } \\
\text { become better and their educational attainments improve...' } \\
\text { 'it is in this way that they are trying to return to [life as it was] before, building like it was...' }\end{array}$ \\
\hline $\begin{array}{l}2 \text { The phases of narrative coherence } \\
\text { - Spiritual identification: confirming belief } \\
\text { in higher power's actions and purpose }\end{array}$ & $\begin{array}{l}\text { 'the biggest thing in these situations is than one reaffirms belief in God. If He wants to keep us } \\
\text { alive, He will find a way and if He wants us to die.... He gives life...' } \\
\text { 'the immediate thing was confidence in God...' } \\
\text { 'we told [the children] that this was God's test for us.' } \\
\text { 'after being steadfast, after a period of difficulty, things get easier. So God again brings our } \\
\text { lives towards normality...' }\end{array}$ \\
\hline $\begin{array}{l}\text { - Spiritual reconstruction: engendering } \\
\text { hope, morale and a new sense of purpose }\end{array}$ & $\begin{array}{l}\text { 'I reasoned that those who have gone, the loss that has happened, that is not going to return. } \\
\text { What should be done is to save that which remains...' } \\
\text { 'to normalise things we have to increase each other's spirits...' }\end{array}$ \\
\hline $\begin{array}{l}\text { - Regaining emotional composure: making } \\
\text { time to process emotions, feelings and } \\
\text { memories }\end{array}$ & $\begin{array}{l}\text { 'The grief is there and comes to my mind sometimes. But we have struggled a lot, especially in } \\
\text { the school. I have given more time to it...' } \\
\text { 'after the earthquake they were saying, "Who needs to live now? Who needs to die now?". } \\
\text { Every home had tears...' } \\
\text { 'after the earthquake we were affected. Slowly, when the grief lessened, we found strength...' }\end{array}$ \\
\hline
\end{tabular}


adjusting to losses, living with continuing threats to safety and security, being vulnerable, trying to meet the challenges of day-to-day survival and so on. Quotes from respondents are grouped into the emergent progression in Table 2.

\section{Phases of social cohesion}

Initial feelings of being utterly overwhelmed by disaster appear to evolve into a series of tentative practical steps to create circumstances conducive to continued personal survival. An element described by participants driving coordinated responses to crises was an explicit recognition of shared loss, suffering and the need once again to feel safe. These statements suggest that immediate survival calls for an individualistic response, but soon thereafter, survival imperatives are served through communal actions and the reaffirmation of normality.

\section{Phases of narrative coherence}

Unprecedented destruction in living memory provoked significant challenges to previously held spiritual beliefs, personal values and psychological attitudes. In the face of massive suffering and destruction, some realignment had to be made to the premises and values by which life had previously been lived. The psychological imperative (for both individuals and groups) was to search for ways of reinterpreting established beliefs in the light of new realities. Once achieved, this engendered a sense of meaning and purpose relevant to ongoing survival. Participants' statements demonstrate that continued coherence of beliefs and values both parallels and dovetails with physical reconstruction for primary needs and fosters social cohesion.

\section{Discussion}

All respondents spontaneously described great personal and societal loss. Interviews were held more than 2 months after the earthquake, when survivors were still in the early stages of adjustment but late enough to minimise psychological debriefing effects. However, emphasis was also placed on capturing these narratives at a time when they were still fresh and therefore arguably more valid. Respondents were in general highly educated and of standing in the community (Table 1), which may reflect in the experiences reported, as they inherently had roles to fit into.

These narratives shed interesting light on the processes of progression from immediate personal despair through accommodation and eventual adjustment to new realities of post-disaster survival (Janoff-Bulman, 1992). They also reaffirm, in line with the literature in this field, the importance of the essential emergency response supporting survival by prioritising basic physical provisions (e.g. food, water, shelter, healthcare).

Survivor narratives bear witness to already present reservoirs of personal, familial and community resilience and resourcefulness in the face of mass disaster. Our understanding of its constituent parts may help improve future disaster-preparedness work (Norris et al, 2008). The evidence of this investigation points to the essential role of institutional (religious, spiritual) and organisational (schools) rituals in facilitating the redevelopment of credible personal and community narratives that confirm affiliations and create hope and feelings of group cohesion. Survivors are indeed 'first responders'; it is therefore important that emergency relief work and humanitarian agencies recognise and work through local groups and affected persons whenever possible. The findings lend support to previously published work (Makdum \& Javed, 2006).

Some of Durkheim's observations on religion as a source of social integration (Durkheim, 1912) resonate with the quoted survivor narratives. This also lends support to more recent publications about the importance of religion and spirituality in fostering adaptive coping strategies after disaster and trauma (Taylor, 2001; Ford et al, 2003). To this end, the objectives of the emergency response should specifically include community leaders and their affiliated institutions. Practical, action-oriented programmes that bolster community cohesion and facilitate emotional processing are required to re-establish a shared sense of personal and community cohesion (Simonsen \& Reyes, 2003).

\section{Limitations of the study}

Participants in this study were teachers and religious leaders selected to attend a training workshop to develop their roles as post-disaster helpers in their local communities. By implication they are likely to have higher educational achievement than other community members, and are less likely to be severely physically injured and not functionally debilitated by trauma-related reactions. Consequently, however, they were in a position to be those who had adjusted, and therefore provide insights as to what helped them in that process. Their descriptions may be biased towards minimising past and current adjustment difficulties. Furthermore, this group did not include children and adolescents.

\section{Conclusion}

The implementation of disaster relief programmes in areas like Kashmir present great challenges to planners and providers of emergency assistance. Our interviews, though limited in number, lead to these observations. Survivors emphasise the importance of emergency relief efforts prioritising primary needs. Communities show resilience and can be strengthened when emergency relief and humanitarian aid organisations work though local groups, such as schools and religious community leaders. The early adjustment of key survivor helpers can assist societal recovery.

\section{Acknowledgements}

We are indebted to the people of Bagh who consented to being interviewed and related their experiences. T.R.A. was a member of the Psychological Support Programme Team of the Qatar Red Crescent Society visiting Bagh.

\section{References}

Cetin, M., Kose, S., Ebrinc, S., et al (2005) Identification and posttraumatic stress disorder symptoms in rescue workers in the Marmara, Turkey, earthquake. Journal of Traumatic Stress, 18, 485-489.

Durkheim, E. (1912) The Elementary Forms of Religious Life.

Ford, C., Udry, J., Gleiter, K., et al (2003) Reactions of young adults to September 11, 2001. Archives of Pediatrics and Adolescent Medicine, $157,572-578$ 
Hagh-Shenas, H., Goodarzi, M. A., Dehbozorgi, G., et al (2005) Psychological consequences of the Bam earthquake on professional and nonprofessional helpers. Journal of Traumatic Stress, 18, 477-483

Janoff-Bulman, R. (1992) Shattered Assumptions - Towards a New Psychology of Trauma. Free Press.

Makdum, M. \& Javed, A. (2006) Earthquake in Pakistan and Kashmir: suggested plan for psychological trauma relief work. International Psychiatry, 3(1), 16-18

Niaz, U., Hassan, S., Hassan, M., et al (2006) Prevalence of posttraumatic stress disorder and co-morbid depression in earthquake survivors in NWFP, Pakistan: a preliminary study. Journal of Pakistan Psychiatric Society, 3, 98-101.
Norris, F., Stevens, S., Pfefferbaum, B., et al (2008) Community resilience as a metaphor, theory, set of capacities, and strategy for disaster readiness. American Journal of Community Psychology, 41, 127-150.

Simonsen, L. F. \& Reyes, G. (2003) Community-Based Psychological Support - A Training Manual (1st edition). International Federation of Red Cross and Red Crescent Societies.

Taylor, A. J. (2001) Spirituality and personal values: neglected components of trauma treatment. Traumatology, 7, 125-135.

Van Griensven, F., Chakkraband, M., Theinkura, W., et al (2006) Mental health problems among adults in tsunami-affected areas in southern Thailand. JAMA, 296, 537-548.

\section{Introducing competency-based training in Europe: an Anglo-Dutch perspective}

\section{Clare Oakley, ${ }^{1}$ Amit Malik ${ }^{2}$ and Femke Kamphuis ${ }^{3}$}

'Specialty Registrar, Queen Elizabeth Psychiatric Hospital, Birmingham B15 2QZ, UK, email clareoakley@doctors.org.uk 2President, European Federation for all Psychiatric Trainees (EFPT), Gosport War Memorial Hospital, Gosport, Hampshire PO12 3PW, UK ${ }^{3}$ Psychiatric trainee, Symfora Groep location Zon en Schild, Utrechtseweg 266, Amersfoort, The Netherlands

$T^{T}$ here are striking and significant differences in psychiatric training across Europe and procedures for the assessment of trainees vary widely (Strachan, 2007). The introduction of competency-based training represents a major shift in medical education and a challenge to harmonising psychiatric training in Europe. This paper discusses the development and implementation of competency-based training in the Netherlands and the UK and focuses on its effects on trainees.

\section{Structure of training}

The structure of medical training and postgraduate training in psychiatry in the UK and the Netherlands is largely similar. However, the minimum duration of postgraduate training is 1.5 years shorter in the Netherlands and there are fewer subspecialties that Dutch trainees can qualify in.

\section{Drivers for change}

In 2004, the Dutch health minister adopted recommendations made by a committee investigating the reorganisation of healthcare. It was recommended that the training of health professionals be more focused on everyday practice and that professionals with a high degree of skill and experience be used to perform only certain tasks, those that could not be done by other, less well-trained, and thus less expensive, professionals. These recommendations were also related to a Dutch report on the division of tasks among mental health professionals (Vleugel et al, 2008). Conceptually, this is similar to 'New Ways of Working' in the UK, which aims to use the skills, knowledge and experience of consultant psychiatrists to best effect by concentrating on those patients with the most complex needs and encouraging other team members to take on increased responsibility (Department of Health, 2005).
In the Netherlands, it has been felt for some time that trainees should not be judged only on their knowledge and practical skills, but also systematically assessed on broader competencies, such as team-working skills, communication skills and professionalism. Additionally, more emphasis on the transparency of healthcare organisations, not only regarding financial aspects, but also regarding training and treatment strategies, has led to greater use of care pathways (diagnosis and treatment combinations) and records of activities performed by health professionals. Organisations receive their funding according to predefined tariffs that are based on diagnosis-treatment combinations, and this puts more pressure on professionals to perform certain tasks in a limited amount of time. Training is not part of these provisions and so in 2008 the funding of training will be changed. In the UK, financial arrangements for healthcare funding are also changing along Dutch lines, with the introduction of payment-by-results, which essentially bases funding on predefined tariffs for care pathways. Once again, there are no set tariffs for training and the manner in which training is funded centrally may change.

In 2005, the Postgraduate Medical Education and Training Board (PMETB) became the UK's statutory body for quality and standards in postgraduate medical education. The new competency-based curriculum approved by the PMETB (Royal College of Psychiatrists, 2006) focuses achievement in medical training on the attainment of specific competencies related not only to clinical care but also to broader skills, as mentioned above. Consequently, the performance of the doctor in the workplace will provide a more robust measure of overall competence. The PMETB is required to approve all aspects of the curriculum and assessment programme, and has recommended an overarching assessment strategy consisting of workplace-based assessments and examinations of knowledge and clinical skills (Bhugra, 2006). A variety of workplace-based assessments (WPBAs) have been developed to allow trainees to demonstrate the required competencies. 